\title{
The Influence of Place Making's Attributes on the Resident's Usage and Satisfaction in High-Rise Residential Community: A Case Study
}

\author{
Ardalan Aflaki ${ }^{1 a}$, Norhayati Mahyuddin², Mozhgan Samzadeh³, Mahsan Mirnezhad ${ }^{4}$ \\ 1,2,3 Center for Urban Conservation and Tropical Architecture (UCTA), Faculty of Built Environment, University of Malaya, Malaysia \\ 4. Department of Architecture, Faculty of Built Environment, University of Malaya, 50603, Kuala Lumpur,Malaysia
}

\begin{abstract}
The vitality and viability of open spaces in urban neighborhoods, particularly in high-density residential areas with limited buildable land, have become extremely complex phenomenon. Researchers and designers are seeking the standard of designed environment to successfully meet the human needs and desires. In order to reach this goal, limited studies have been implemented to bridge the gap between research and design and consequently improve the physical and social qualities of open spaces. This paper examines the two specific features of open space - accessibility, social interactions - which contribute significantly to both the vitality and viability with a view to provide an understanding of the relative importance of these elements from users' perceptions and satisfaction. The methods involve quantitative research with questionnaire-based survey, and case study to evaluate residents' perceptions. The research scope is a highdensity residential condominium in Kuala Lumpur where the rapid transformation of urban elements in city center has negative impacts on basic qualities of open spaces. The result is a framework for understanding the relative priority of the different elements (variables) for users which vary depending on the location of the residential block they live in; in particular its proximity to the open space. The study concludes with recommendations for how the most valuable elements can be better harnessed in order to promote the satisfaction with open spaces.
\end{abstract}

Keywords: Open spaces, Accessibility, Social interaction, User satisfaction, high density residential areas

\section{Introduction}

Open spaces are a significant element contributing to sustainability. They can help create a healthy environment, and ensure the viability and vitality of urban neighbourhoods. Bedmio-Rung et, al.[1] meanwhile noted that, while cities have many elements, open spaces can connect residential districts to all the other parts of a city. Open spaces in neighbourhoods can also bring a sense of community and help forge closer relationships among neighbours because they can act as a node for social gatherings or ceremonies [2]. In addition, the greenery within open spaces can moderate the local micro-climate, create a sense of relaxation, provide welcome shade and increase the positive aesthetic feelings of residents. This study examines the value of selected features in a high density residential area in order to understand which elements are most important for residents in terms of usage and satisfaction levels.

\footnotetext{
${ }^{\text {a }}$ Corresponding author: ar.aflaki@siswa.um.edu.my
}

\section{Factors and their influence on the physical and social quality of open space}

There are a lot of potential factors that can influence the quality of open spaces. Accessibility, climate comfort, facilities and amenities, and aesthetic values are among the physical factors, while safety, privacy, social interaction and surveillance are important social factors which can impact on the quality of open space. The current study focuses on accessibility and social interaction in open spaces in a high density residential area which is typical of the recent rapid transformation of residential developments in Kuala Lumpur. 


\subsection{Accessibility}

Levinson [3] measured accessibility with two variables: travel time between two destinations, and the distribution of land use (close proximity). Close proximity and visual accessibility to open spaces are two main indicators of a well-designed urban space [4]. Physical and locational features such as proximity to the park and adequate amount of parks nearby could impact perceived accessibility to urban parks [5]. Location, design and linkages with other types of area are other significant factors which can attract people to open space [6].

Linkages and connections enhance the quality of open spaces and the degree of user satisfaction, by connecting activities which happen within and near open spaces [7]. Distance to and from an open space is one of the indicators of how well that space is connected. There are a lot of methods to measure distance. One such is the shortest network path, which is defined by the shortest (short-cut) distance to an open space[8]. Talen [9] also devised methods to calculate the minimum travel distance from residential units to open spaces, as well as the accessibility of open spaces. There is as yet no consensus over the best method to evaluate accessibility to open spaces. Table 1 shows the variables used in this research to evaluate accessibility from units to the open space.

Table 1. Variables for measurement of accessibility

\begin{tabular}{|c|c|}
\hline Variable & Reference \\
\hline $\begin{array}{c}\text { Close proximity } \\
\text { Ability to achieve basic needs } \\
\text { Good visibility } \\
\text { Access to other competing local facilities }\end{array}$ & $\begin{array}{l}\text { Giles-Crti et } \\
\text { al.2005[4] }\end{array}$ \\
\hline Location & Calthorpe 1993[6] \\
\hline Travel time & [10] \\
\hline $\begin{array}{c}\text { Context linkage system: location of the space } \\
\text { Physical and visual permeability }\end{array}$ & $\begin{array}{l}\text { Heng and Chan } \\
2000[11]\end{array}$ \\
\hline Shortest network paths & Truelove 1993[8] \\
\hline Diversity & Talen 2000[9] \\
\hline
\end{tabular}

\subsection{Social interaction}

Social contacts are another significant factor for attracting people to urban open spaces [12]. Social interaction creates liveliness, vitality and viability in open spaces [13]. There are many variables which can measure social interaction within open spaces. According to Chiesura [14], variables which can help to evaluate the impact of social interaction on the quality of an open space include the volume of interactions and contacts with other people, the use of the land beside the open space, and the reasons users give for using an open space (such as meeting neighbours and social activities).

Social activities such as social interactions are more likely to happen within open spaces when the level of physical and social amenities is good [15]. Urban parks play a vital role to improve human well-being under environmental disorders [16]. Conversely, good quality open spaces can provide better environments for residents' activities and encourage them to use open spaces more [13]. In sum, the amount, type and presence of users and their activities as well as the quality of the open space can impact on social interactions within it. Table 2 shows the variables used in this study to measure social interaction within open spaces.

Table 2. variables for measurement of social interaction

\begin{tabular}{|c|c|}
\hline Variable & Reference \\
\hline Social interaction in spite of activities & Chiesura 2003[14] \\
\hline $\begin{array}{c}\text { Social interaction \& being with } \\
\text { others } \\
\text { Participation in activities }\end{array}$ & Gedikli 2004[12] \\
\hline Presence of users in open space & Moirongo 2002[15] \\
\hline
\end{tabular}

\subsection{High density and its effects on open space}

High density developments have a number of advantages. They can provide better social interaction, high levels of security and safety, and also a comfortable environment for residents who want to walk, relax or otherwise take their leisure in a given neighbourhood [13]. By providing a balance between residential, commercial and official activities, such developments can increase the sense of security and safety among residents $[13,17]$. According to Liao et al. [18] around $40 \%$ of the respondents choosing neighbourhoods with friendly environment for walking or biking. On the other hand, some research mentions various negative points related to high density, such as overcrowding, lack of privacy and restricted living space for residents [19].

With regard to open spaces, there are, again, both positive and negative arguments about high density. For instance, high density city life is generally much better than low density suburban living in relation to social community as well as the social quality of open spaces. Rowley [20] argued that, when high density living is accompanied by a good distribution of mixed use in a city; this can offer diversity of use with vitality. Also, high density with its closer social contacts and interaction among residents offers more opportunity for neighbours to do recreational activities in their spare time $[13,17]$. The same authors also suggested that high density dwellings can save land, leaving more free land in which to design open spaces and greenery in residential neighbourhoods, although he also noted some negative aspects of high density, such as limited scope to create and enjoy greenery. Overall, negative environmental impacts tend to be greater in urban sprawl, and there is less scope for sustainable design in such environments. Newman [21] mentioned that low density sprawling cities suffer from poor environmental quality for residents, with adverse effects on health. In contrast, in high density cities dependency on cars is much lower, which can have positive impacts on air quality and the natural environment around residential buildings, making these more conducive for residents to use open spaces, breath fresh air, and sit and gather for social interactions. 
In conclusion, although high density living can support sustainable, quality living in part, more research is needed into the negative aspects and how to solve these $[19,20]$ in order to establish if urban high density developments can be a widely viable option for sustainable developments in the future.

\subsubsection{The impacts of high density living on accessibility and social interaction in open spaces}

There is an expanding base of literature on the implications of high density living for the social quality of open spaces within neighbourhoods. Many of these studies concern the arrangement and distribution of primary and secondary activities. Hillier and Hanson [22] claimed that these arrangements could directly influence the intensity of social interactions. Social activities and contacts could also be persuading when high density of primary and secondary activities happen in suitable and relevant condition [15, 23]. While mixed land use in high density areas creates good opportunities for social interaction, it can on the other hand cause some difficulties such as lack of safety and privacy. Another challenge related to mixed land use developments is encroachment on public areas. For example, where privately owned restaurants or shops are adjacent to public open spaces, it becomes difficult to separate the public space and from the private space and controls may be necessary $[13,21]$.

\section{Research methodology and design}

This study adopts a quantitative methodology, using the questionnaire technique to evaluate selected features in open spaces based on user preferences. The data from survey questionnaires is then analysed by comparing crosstabulations. This focus on users' opinions, and their perceptions of the recreational space, are key sources of information and criteria on open space design [24].

In the current study, the questionnaire consists of three parts, as detailed below:

- General questions on participants, such as their gender and age.

- Information on the residents' (participants') opinions on the physical aspects of the place in question.

- Questions examining the social qualities related to the place and its attributes.

A five-point Likert scale is used for answers, ie: strongly disagree, disagree, neutral, agree, and strongly agree. A content analysis is first used to present established theories relating to the attributes of the place and their influence on the quality of the open space. Consequently, a cross-tabulation from the survey questionnaires is applied to further analyse the findings.

In this study, the residents sampled live in the East Lake condominium in the district of Serdang. The primary field survey in the current study assured that the range of resident's age who were using the open space regularly was between 15 to 65 years old. Thus, the study designed a survey questioner in order to collect the data for the above mentioned range. The survey questionnaires were distributed within open spaces in their respective units to identify and study differences and similarities in ideas among residents. A total of 84 responses were collected out of 140 questionnaires given out.

\subsection{Study area}

The study area is a high density residential condominium located in the district of Serdang in Kuala Lumpur. It contains five blocks of 19-storey buildings. There is a total of 618 residential units in East Lake condominium. A bird's eye view, showing the layout of all the blocks in the study area, is presented in Figure 1. Figure 2 shows the site plan of the condominiums, with the blocks marked by circles. The arrows indicate the possible routes from the blocks to the open space area, which is marked by a black circle. The pictures in Figures 3 and 4 show the open space and its connections with some of the surrounding facilities, such as a reading room, gymnasium, restaurant, mini-markets and laundry; they also show the residents engaging in activities. A narrow pathway which links Blocks D and $\mathrm{E}$ is shown in Figure 4. Residents living in Blocks D and $\mathrm{E}$ have to walk alongside two further blocks to reach the open space.

\subsection{Scope and limitation of study}

The current study was limited to the open spaces in the highincome and high-rise residential building in Kuala Lumpur. There were few studies on the quality of open space with regards to social and physical qualities [16]. As a result, the current study focused on these attributes. Therefore, the main scope of this study was the evaluation of open space quality in the high-rise building where the quite numbers of residents were living in the dense area.

This caused the quality of open space in these residential communities be questionable.

The study faced to certain limitation on selection of study area. In the primary survey, the study selected the total numbers of 5 residential communities with the equipped open spaces. However, due to security and privacy reasons, the management offices did not permit the researcher to collect the data. Among the selected condominium for the study, the researcher got permission from the management office of East lake condominium in the Serdang. 


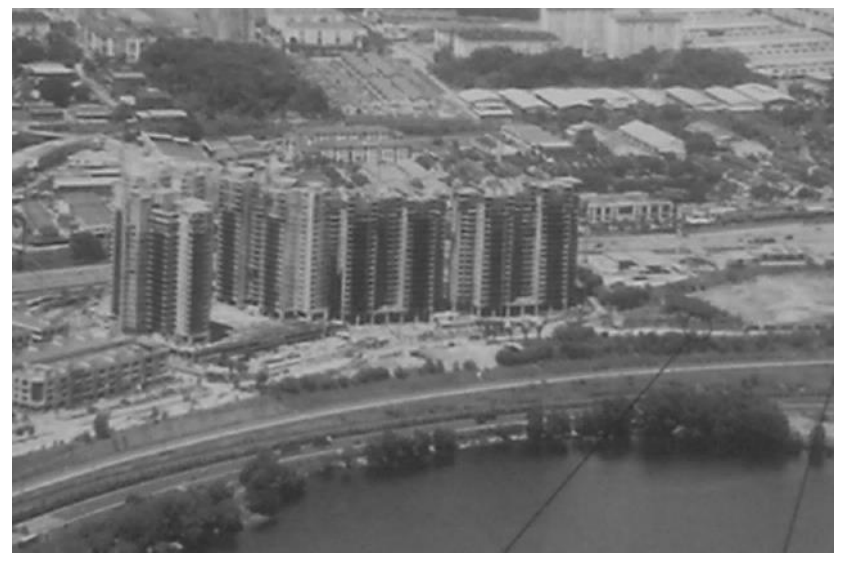

Figure 1. Bird's eye view of case study (Source: Authors, 2013)

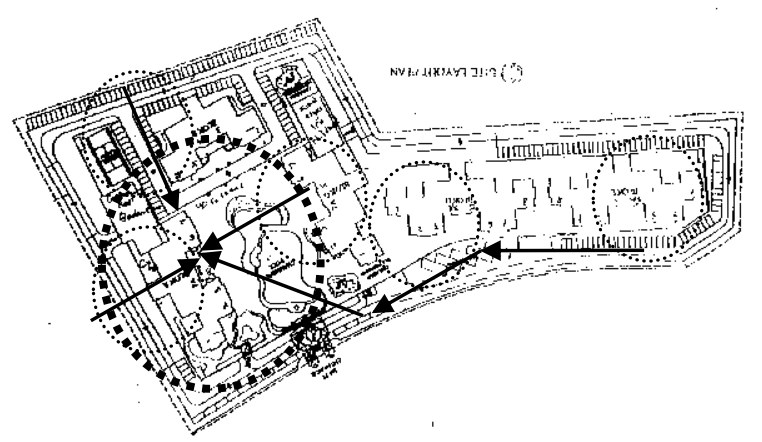

Figure 2 Site plan and arrangement of blocks (Source: Authors, 2013)

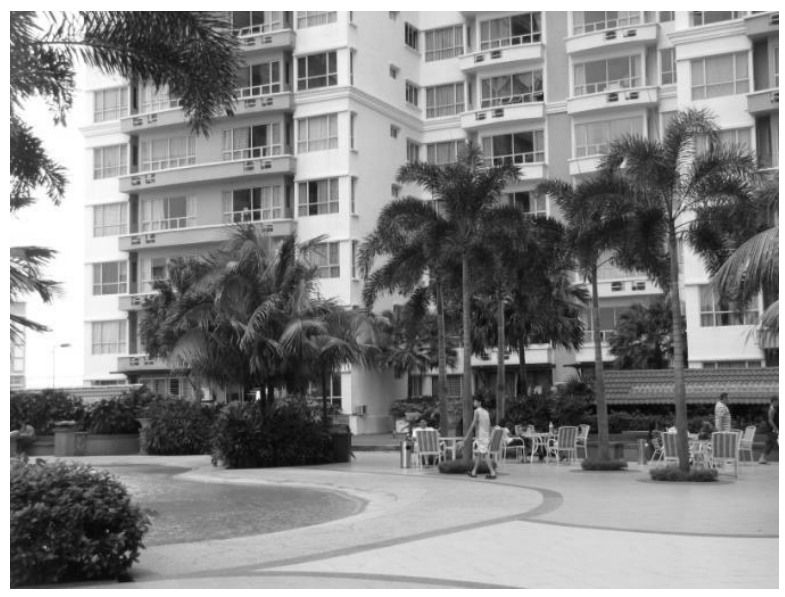

Figure 3. Swimming pool and it's alongside activities in open space (Source: Authors, 2013)

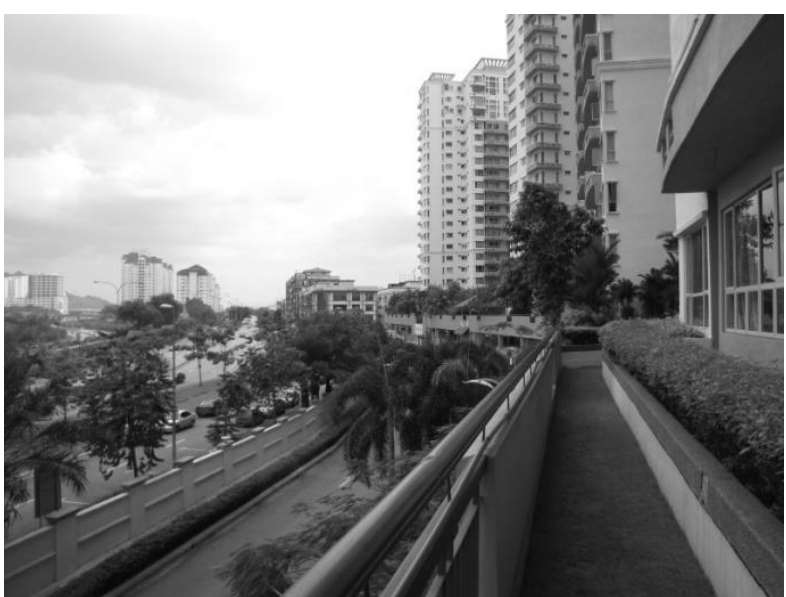

Figure 4. Connected Pathway from blocks D and E to open space (Source: Authors, 2013)

\section{Results and discussion}

As the current research focuses on two most important factors which influence open space use and satisfaction: accessibility and social interaction in the open space, the analysis of results is presented consequently. Accessibility consists of two variables: travel time/distance between two points, and the distribution of land use within reasonable proximity $[3,10]$. Location, close proximity, short travel distances, land use surrounding open spaces and the design of open spaces themselves are all significant factors in bringing residents together [6]. Table 3 explains all the above mentioned variables used in this study to examine the degree of accessibility in the Case study. The findings show that the majority of respondents agreed or strongly agreed that accessibility to basic needs (57 respondents), open space location (53 respondents) and close proximity (51 respondents) are important factors for accessibility. In contrast, a majority of respondents disagreed or strongly disagreed that having a variety of accessible ways (54 respondents) and having network paths among blocks (48 respondents) are important factors. Table 4 contains a crosstabulation of close proximity and four other variables, namely gender, age, the block where respondents live, and travel time. It shows that respondents who stay and live in Blocks A, B or $\mathrm{C}$ represent the majority of respondents who agreed or strongly agreed that close proximity and travel time to reach the open space are important. The last columns show the total numbers agreeing about close proximity and also present the percentages of residents who participated in survey in the different blocks. Most of the respondents in Block A (11 of 13 or $84.6 \%), 94.1 \%$ of respondents in Block B (16 out of 17 ) and all of the dwellers in Block $\mathrm{C}(100 \%)$ in different categories of ages and genders agreed or strongly agreed that distance to the open space is important. 
Table 3. Evaluation of accessibility degree based on respondent's idea

\begin{tabular}{|c|c|c|c|c|c|}
\hline $\begin{array}{c}\text { Measurements of accessibility base on } \\
\text { variable }\end{array}$ & $\begin{array}{c}\text { Strongly } \\
\text { disagree }\end{array}$ & Disagree & Neutral & Agree & $\begin{array}{c}\text { Strongly } \\
\text { agree }\end{array}$ \\
\hline Close proximity & 6 & 19 & 8 & 27 & 24 \\
\hline Sidewalk diversity & 4 & 18 & 23 & 28 & 11 \\
\hline Network paths among blocks & 13 & 33 & 22 & 15 & 1 \\
\hline Open space location & 5 & 14 & 12 & 42 & 11 \\
\hline Travel time & 4 & 23 & 10 & 30 & 17 \\
\hline Surrounding's linkages & 1 & 15 & 24 & 32 & 12 \\
\hline Visibility & 19 & 21 & 4 & 15 & 25 \\
\hline Accessibility to basic needs & 0 & 2 & 20 & 42 & 15 \\
\hline Variety of accessible ways & 20 & 34 & 17 & 11 & 2 \\
\hline Permeability & 1 & 20 & 18 & 36 & 9 \\
\hline
\end{tabular}

The last column in Table 4 show the number of residents from the more distant blocks who disagreed or strongly disagreed that close proximity to the open space is important - note that these are people who have to pass other blocks to reach the open space. Fully $65 \%$ of the dwellers in Block D (13 of 20 persons) and $84.2 \%$ of residents in Block E (16 of 19 persons) fell into these categories. In other words, the results demonstrate that easy access and close proximity to the open space are important aspects for respondents in Blocks A, B and $\mathrm{C}$. However, this raises the question: "Why do those living in Blocks D and E use the open space if they do not generally agree that close proximity is important?" An analysis of the results for greenery and landscape answers this critical question.

In conclusion, the analyses show that respondents in Blocks $\mathrm{A}, \mathrm{B}$ and $\mathrm{C}$ prefer to go to the open space mainly because of its close proximity and short travelling distance. However, respondents in Blocks D and E perceive the landscape features in the open space as important elements which encourage them to go there to spend their spare time. Aside from these reasons, social interaction is another reason for residents going to and staying in the open space.

Getting together, relaxing, appreciating nature, being with children and doing different kinds of activities were further reasons given for going to the open space. Table 5 analyses how far respondents see the open space as an opportunity to be with other neighbours, and the relative degree of agreement in different categories of age, gender and residential block. The figures show that there is broad agreement among respondents that the open space serves as a place for gathering and being with others. This holds for all of the blocks, although the proportions agreeing are slightly higher in the more distant blocks. Thus $61.5 \%$ of residents in Block A, $70.5 \%$ in Block B, $73.3 \%$ in Block C, $80 \%$ in Block D and $73.6 \%$ in Block $\mathrm{E}$ either agreed or strongly agreed that social contacts are one of the main reasons they go to and use the open space.

\section{Conclusions and recommendations}

The results of this survey show that residents in East Lake condominium come to the open space for four main reasons: closeness/short distance to the open space (physical accessibility); visual accessibility from their residential units to the open space and the opportunity for social interaction, eg with other residents. Although all of these are significant reasons, the degree of agreement on their relative importance varies amongst respondents from different blocks. Residents in Blocks A, B and C, which are located next to the open space, mostly have direct visual access to it from their own windows, and tend to consider visual and physical accessibility (proximity) as the main reasons for going to the open space and social interaction as only secondary reasons. This contrasts with residents in Blocks D and E, who live physically further away from the open space and have no direct visual access to it: they mainly go there because of opportunities for social interaction, with accessibility (eg pathways) and visual permeability as only secondary reasons. This suggests that the number of dwellers in Blocks D and E using the open space would be likely to drop if for any reason either the aesthetic value or the opportunities for social activities in the open space fell in the future.

Appropriate design could also help to encourage and facilitate the opportunities for holding social events and experiences in the open space. Creating visual accessibility to open spaces, for example by the use of well-designed and located pathways, is another means of enhancing their use. Visual accessibility could also be enhanced by creating a hierarchy of spaces offering glimpses from the private to public areas, thereby encouraging residents to walk from the private space to the public space with different perspectives from different locations. 
Table 4. Proximity and travel time evaluation based on survey questionnaire in separated blocks

\begin{tabular}{|c|c|c|c|c|c|c|c|c|c|c|c|c|c|c|}
\hline \multirow{2}{*}{\multicolumn{2}{|c|}{$\underset{\text { time }}{\text { proximity } \& \text { travel }}$}} & \multirow{2}{*}{$\begin{array}{l}\text { Male } \\
15-25 \\
\end{array}$} & \multirow{2}{*}{$\begin{array}{l}\text { Male } \\
25-35\end{array}$} & \multirow{2}{*}{\begin{tabular}{|c|} 
Male \\
$35-45$
\end{tabular}} & \multirow{2}{*}{\begin{tabular}{|l|} 
Male \\
$45-55$ \\
\end{tabular}} & \multirow{2}{*}{$\begin{array}{c}\text { Male } \\
55-65\end{array}$} & \multirow{2}{*}{$\begin{array}{c}\text { Male } \\
65 \text { or } \\
\text { above }\end{array}$} & \multirow{2}{*}{\begin{tabular}{|c|} 
Female \\
$15-25$
\end{tabular}} & \multirow{2}{*}{$\begin{array}{c}\text { Female } \\
25-35 \\
\end{array}$} & \multirow{2}{*}{\begin{tabular}{|c|} 
Female \\
$35-45$ \\
\end{tabular}} & \multirow{2}{*}{\begin{tabular}{|c|} 
Female \\
$45-55$ \\
\end{tabular}} & \multirow{2}{*}{$\begin{array}{c}\text { Female } \\
55-65\end{array}$} & \multirow{2}{*}{$\begin{array}{c}\text { Female } \\
\begin{array}{c}65 \text { or } \\
\text { above }\end{array}\end{array}$} & \multirow[b]{2}{*}{ Total } \\
\hline & & & & & & & & & & & & & & \\
\hline \multirow{5}{*}{ BLOCK A } & St disagree & & & & & & & & & & & & & $\mathbf{0}$ \\
\hline & Disagr & & & & & 1 & & & & & & & & 1 \\
\hline & Neutral & & & & & & 1 & & & & & & & 1 \\
\hline & Agree & & & 2 & 1 & & & & 2 & & & & & 5 \\
\hline & St agree & & 1 & & 1 & & & 1 & 1 & & 1 & 1 & & 6 \\
\hline \multicolumn{2}{|c|}{ ROW PERCENT } & $0.00 \%$ & $7.69 \%$ & $15.38 \%$ & $15.38 \%$ & $7.69 \%$ & $7.69 \%$ & \begin{tabular}{|l|}
$7.69 \%$ \\
\end{tabular} & $23.07 \%$ & $0.00 \%$ & $7.69 \%$ & $7.69 \%$ & $0.00 \%$ & $13 / 15,51 \%$ \\
\hline \multirow{5}{*}{ BLOCK B } & St disagree & & & & & & & & & & & & & 0 \\
\hline & Disagre & & 1 & & & & & & & & & & & 1 \\
\hline & Neutral & & & & & & & & & & & & & $\mathbf{0}$ \\
\hline & Agree & 2 & & & 1 & & & 1 & & 2 & & & & 6 \\
\hline & St agree & & 1 & 1 & & & & 2 & 2 & 2 & 1 & 1 & & 10 \\
\hline \multicolumn{2}{|c|}{ ROW PERCENT } & $11.76 \%$ & $11.76 \%$ & $5.88 \%$ & $5.88 \%$ & $0.00 \%$ & $0 \%$ & $17.64 \%$ & $12 \%$ & $23.52 \%$ & $5.88 \%$ & $5.88 \%$ & $0.00 \%$ & $17 / 21.23 \%$ \\
\hline \multirow{5}{*}{ BLOCK C } & St disagree & & & & & & & & & & & & & $\mathbf{0}$ \\
\hline & Disagree & & & & & & & & & & & & & $\mathbf{0}$ \\
\hline & Neutral & & & & & & & & & & & & & $\mathbf{0}$ \\
\hline & Agree & & 1 & 1 & 1 & 2 & & 1 & 1 & & 1 & & & 8 \\
\hline & St agree & 1 & & 3 & & & & & 1 & 1 & & 1 & & 7 \\
\hline \multicolumn{2}{|c|}{ ROW PERCENT } & $666 \%$ & $666 \%$ & $2666 \%$ & $666 \%$ & $1333 \%$ & $0 \%$ & $666 \%$ & $1333 \%$ & \begin{tabular}{|l|}
$666 \%$ \\
\end{tabular} & $666 \%$ & $666 \%$ & $0 \%$ & $15 / 17.85 \%$ \\
\hline \multirow{5}{*}{ BLOCK D } & St disagree & & & & 1 & & 1 & & & & & 2 & & 4 \\
\hline & Disagree & 1 & & & & & & 3 & 2 & 1 & 1 & 1 & 1 & 9 \\
\hline & Neutral & & & 1 & & & & & 1 & 1 & & & & 3 \\
\hline & Agree & 1 & 1 & & & & & & & 1 & & & & 3 \\
\hline & St agree & & & 1 & & & & & & & & & & 1 \\
\hline \multicolumn{2}{|c|}{ ROW PERCENT } & $10 \%$ & $5 \%$ & $10 \%$ & $5 \%$ & $0 \%$ & $5 \%$ & $15 \%$ & $15 \%$ & $15 \%$ & $5 \%$ & $15 \%$ & $5 \%$ & $20 / 23.80 \%$ \\
\hline \multirow{5}{*}{ BLOCK E } & St disagr & & & & 2 & & & 1 & & 1 & 1 & & & 5 \\
\hline & Disagree & 3 & 1 & & 1 & 1 & & 1 & 2 & & 1 & & 1 & 11 \\
\hline & Neutral & & 1 & & & & & & & & & & & 1 \\
\hline & Agree & & & 1 & & & & & 1 & & & & & 2 \\
\hline & St agree & & & & & & & & & & & & & 0 \\
\hline \multicolumn{2}{|c|}{ ROW PERCENT } & \begin{tabular}{|l|}
$15.78 \%$ \\
\end{tabular} & $10.52 \%$ & $5.26 \%$ & $15.78 \%$ & $5.26 \%$ & $0 \%$ & \begin{tabular}{|l|}
$10.52 \%$ \\
\end{tabular} & $15.78 \%$ & $5.26 \%$ & $10.52 \%$ & $0 \%$ & $5.26 \%$ & $19 / 22.61 \%$ \\
\hline
\end{tabular}

Table 5. Social interaction evaluation based on survey questionnaire in separated blocks

\begin{tabular}{|c|c|c|c|c|c|c|c|c|c|c|c|c|c|c|}
\hline \multirow{2}{*}{\multicolumn{2}{|c|}{ Social interaction }} & Male & Male & Male & Male & Male & Male & Female & Female & Female & Female & Female & Female & \multirow{2}{*}{ Total } \\
\hline & & \multirow[t]{6}{*}{$15-25$} & \multirow[t]{5}{*}{$25-35$} & \multirow[t]{3}{*}{$35-45$} & \multirow[t]{4}{*}{$45-55$} & \multirow[t]{4}{*}{$55-65$} & \multirow[t]{4}{*}{ 65or above } & \multirow[t]{3}{*}{$15-25$} & \multirow[t]{2}{*}{$25-35$} & \multirow[t]{6}{*}{$35-45$} & \multirow[t]{2}{*}{$45-55$} & $55-65$ & \multirow[t]{6}{*}{65 or above } & \\
\hline \multirow{5}{*}{ BLOCK A } & St disagree & & & & & & & & & & & & & $\mathbf{0}$ \\
\hline & \begin{tabular}{|l|} 
Disagree \\
\end{tabular} & & & & & & & & 1 & & 1 & & & 2 \\
\hline & Neutral & & & 2 & & & & 1 & & & & & & 3 \\
\hline & Agree & & & & 2 & 1 & 1 & & 2 & & & & & 6 \\
\hline & St agree & & 1 & & & & & & & & & 1 & & 2 \\
\hline \multicolumn{2}{|c|}{ ROW PERCENT } & $0 \%$ & $7.69 \%$ & $15.38 \%$ & $15.38 \%$ & $7.69 \%$ & $7.69 \%$ & $7.69 \%$ & $23.10 \%$ & $0.00 \%$ & \begin{tabular}{|l|}
$7.69 \%$ \\
\end{tabular} & $7.69 \%$ & $0.00 \%$ & $13 / 15,51 \%$ \\
\hline \multirow{5}{*}{ BLOCK B } & St disagree & & & & & & & & & & & & & 0 \\
\hline & \begin{tabular}{|l|} 
Disagree \\
\end{tabular} & 1 & & & 1 & & & & & 1 & & & & 3 \\
\hline & Neutral & 1 & & & & & & & 1 & & & & & 2 \\
\hline & Agree & & 2 & 1 & & & & 2 & 1 & 1 & & 1 & & 8 \\
\hline & St agree & & & & & & & 1 & & 2 & 1 & & & 4 \\
\hline \multicolumn{2}{|c|}{ ROW PERCENT } & $11.76 \%$ & $11.76 \%$ & $5.88 \%$ & $5.88 \%$ & $0.00 \%$ & $0 \%$ & $17.68 \%$ & $12 \%$ & $23.52 \%$ & \begin{tabular}{|l|}
$5.88 \%$ \\
\end{tabular} & $5.88 \%$ & $0.00 \%$ & $17 / 21.23 \%$ \\
\hline \multirow{5}{*}{ BLOCK C } & St disagree & & & & & & & & & & & & & 0 \\
\hline & \begin{tabular}{|l|} 
Disagree \\
\end{tabular} & & & & & 2 & & & & & & & & 2 \\
\hline & Neutral & & & & 1 & & & & & 1 & & & & 2 \\
\hline & Agree & & & 2 & & & & 2 & 3 & & & & & 7 \\
\hline & St agree & & 1 & 2 & & & & & & & 1 & & & 4 \\
\hline \multicolumn{2}{|c|}{ ROW PERCENT } & $0 \%$ & $666 \%$ & $2666 \%$ & $666 \%$ & $1333 \%$ & $0 \%$ & $666 \%$ & $1333 \%$ & $666 \%$ & $672 \%$ & $0 \%$ & $0 \%$ & $15 / 17.85 \%$ \\
\hline \multirow{5}{*}{ BLOCK D } & \begin{tabular}{|l|} 
St disagree \\
\end{tabular} & & & & & & & & & & & & & 0 \\
\hline & \begin{tabular}{|l|} 
Disagree \\
\end{tabular} & & & & & & & & & & & & & $\mathbf{0}$ \\
\hline & Neutral & 1 & & & & & & 1 & 1 & & 1 & & & 4 \\
\hline & Agree & & 1 & 2 & 1 & & 1 & 1 & & 2 & & 2 & & 10 \\
\hline & St agree & 1 & & & & & & 1 & 2 & 1 & & & 1 & 6 \\
\hline \multicolumn{2}{|c|}{ ROW PERCENT } & $10 \%$ & $5 \%$ & $10 \%$ & $5 \%$ & $0 \%$ & $5 \%$ & $15 \%$ & $15 \%$ & $15 \%$ & $5 \%$ & $10 \%$ & $5 \%$ & $20 / 23.80 \%$ \\
\hline \multirow{5}{*}{ BLOCK E } & St disagree & & & & & & & & & & & & & $\mathbf{0}$ \\
\hline & Disagree & & & & 1 & & & & & & 1 & & & 2 \\
\hline & Neutral & & 2 & & & & & & & & & & 1 & 3 \\
\hline & Agree & 3 & & & 1 & 1 & & 2 & 1 & 1 & 1 & & & 10 \\
\hline & St agree & & & 1 & 1 & & & & 2 & & & & & 4 \\
\hline \multicolumn{2}{|c|}{ ROW PERCENT } & $15.78 \%$ & $10.52 \%$ & $5.26 \%$ & \begin{tabular}{|l|}
$15.78 \%$ \\
\end{tabular} & $5.26 \%$ & $0 \%$ & $10.52 \%$ & $15.78 \%$ & $5.26 \%$ & \begin{tabular}{|l|}
$10.58 \%$ \\
\end{tabular} & $0 \%$ & $5.26 \%$ & $19 / 22.61 \%$ \\
\hline
\end{tabular}




\section{References}

1. Bedimo-Rung, A.L., A.J. Mowen, and D.A. Cohen, The significance of parks to physical activity and public health: a conceptual model. American journal of preventive medicine, 2005. 28(2): p. 159-168.

2. Pakzad, j., The rule of urban design. 2004, Tehran, Iran: University of Tehran.

3. Levinson, D.M., Accessibility and the journey to work. Journal of Transport Geography, 1998. 6(1): p. 11-21.

4. Giles-Corti, B., et al., Increasing walking: how important is distance to, attractiveness, and size of public open space? American journal of preventive medicine, 2005. 28(2): p. 169-176.

5. Wang, D., G. Brown, and Y. Liu, The physical and non-physical factors that influence perceived access to urban parks. Landscape and Urban Planning, 2015. 133: p. 53-66.

6. Calthorpe, P., The next American metropolis: Ecology, community, and the American dream. 1993: Princeton Architectural Press.

7. Bertolini, L. and M. Dijst, Mobility environments and network cities. Journal of urban design, 2003. 8(1): p. 27-43.

8. Truelove, M., Measurement of spatial equity. Environment and Planning C: Government and Policy, 1993. 11(1): p. 19-34.

9. Talen, E., Measuring the public realm: A preliminary assessment of the link between public space and sense of community. Journal of Architectural and Planning Research, 2000: p. 344-360.

10. Erkip, F.B., The distribution of urban public services: the case of parks and recreational services in Ankara. Cities, 1997. 14(6): p. 353361.

11. Heng, C. and V. Chan, The making of successful public space: A case study of people's park square. Urban Design International, 2000. 5(1): p. 47-55.

12. GEDİKLİ, B., STRATEGIC SPATIAL PLANNING AND ITS IMPLEMENTATION IN TURKEY: SSANLIURFA PROVINCIAL DEVELOPMENT PLANNING CASE. 2004, MIDDLE EAST TECHNICAL UNIVERSITY.
13. Jacobs, J., The Death and Life of Great American Cities. Readings in Planning Theory, Fourth Edition, 2015: p. 94-109.

14. Chiesura, A., The role of urban parks for the sustainable city. Landscape and urban planning, 2004. 68(1): p. 129-138.

15. Moirongo, B.O., Urban public space patterns: human distribution and the design of sustainable city centres with reference to Nairobi CBD. Urban Design International, 2002. 7(3): p. 205216.

16. Scopelliti, M., et al., Staying in touch with nature and well-being in different income groups: The experience of urban parks in Bogotá. Landscape and Urban Planning, 2016. 148: p. 139-148.

17. Masnavi, M.-R., The new millennium and the new urban paradigm: the compact city in practice. Achieving sustainable urban form, 2000: p. 64-73.

18. Liao, F.H., S. Farber, and R. Ewing, Compact development and preference heterogeneity in residential location choice behaviour: A latent class analysis. Urban Studies, 2014: p. 0042098014527138.

19. Williams, K., M. Jenks, and E. Burton, Achieving sustainable urban form. 2000: Taylor \& Francis.

20. Rowley, A., Planning mixed use development: issues and practice. Royal Institution of Chartered Surveyors, London, 1998.

21. Newman, O., N.I.o.L. Enforcement, and C. Justice, Architectural design for crime prevention. 1973: National Institute of Law Enforcement and Criminal Justice Washington, DC.

22. Hillier, B., et al., Natural movement: or, configuration and attraction in urban pedestrian movement. Environment and Planning B: planning and design, 1993. 20(1): p. 29-66.

23. Gehl, J., Life between Buildings (Copenhagen: Arkitektens Forlag). 1996.

24. Manning, R.E. and W.A. Freimund, Use of visual research methods to measure standards of quality for parks and outdoor recreation. Journal of leisure research, 2004. 36(4): p. 557. 